\title{
A Study on the Distribution of Foreign-Female-Isolated Areas in Japan
}

\author{
Kohei OKAMOTO $^{\mathrm{a}, *}$, Masatoshi MORITA ${ }^{\mathrm{b}}$ \\ a Nagoya University, h44540a@cc.nagoya-u.ac.jp, ${ }^{b}$ Gifu Shotoku Gakuen University, mmorita@gifu.shotoku.ac.jp \\ * Corresponding author
}

Keywords: foreign-female-isolated areas, population census, grid square statistics

\section{Abstract:}

The Great East Japan Earthquake in 2011 made a realization of non-Japanese living dispersed in various areas across Japan. The non-Japanese trainees working in the small-size factories in the underpopulated areas and the immigrant wives married to Japanese men in the farming areas were there to compensate for the decreasing Japanese working-age population and the decreasing number of Japanese women who will marry farmers. These women, mostly Chinese and Filipino, live in local communities, isolated from the other non-Japanese residents; they cannot use their mother tongue, they cannot get mutual helps, and they cannot form ethnic community. Their distribution pattern is very different from that in foreigner-concentrated areas in metropolises like Tokyo and Osaka. Ethnicity studies in geography and sociology have mainly focused on foreigner-concentrated areas. There have been few studies on ethnic minorities who live dispersed among their host society. They have been invisible in Japanese society. This study try to clarify where in Japan nonJapanese are living dispersed and develop the method to measure how sparsely they are scattered.

This study analyses the distribution pattern on non-Japanese by using the Grid Square Statistics of 2010 Population Census and GIS. The Grid Square Statistics is one of the small area statistics which divides the whole area of Japan into small mesh. This study uses statistics of $1 \mathrm{~km} \times 1 \mathrm{~km}$ grids (Figure 1 ).

So far, we have seen that the degree of the isolation of the non-Japanese woman is remarkable in north-eastern Japan. For example, among the 3,249 inhabited grids of Yamagata Prefecture, 1,291 of which had non-Japanese residents, 509 had only one non-Japanese, and 479 of those 509 non-Japanese were women. In other words, $15.7 \%$ of the one-squarekilometre inhabited grids in Yamagata Prefecture had only one non-Japanese resident and that person was female, which is the highest among 47 prefectures in Japan. On the other hand, this ratio was relatively low in the metropolitan areas including Kanagawa prefecture and the prefectures of southwestern Japan (Figure 2).

This study identifies the grid which have only one non-Japanese and that person is female as "isolated-grid". In the isolated-grids, there are grids where no foreigners live in the 8 adjacent grids, which could be named as "more-isolatedgrid" (Figure 1). When we calculate the proportions of the grids for each prefecture and draw them with Quantile classification (Figure 3, left), isolated-grids are distributed in eastern Japan such as Tohoku region same as Figure 2. On the other hand, more-isolated-grids are found not only in eastern Japan but also in western Japan such as Kyushu (Figure 3 , right). This is a new finding that has never been said before.

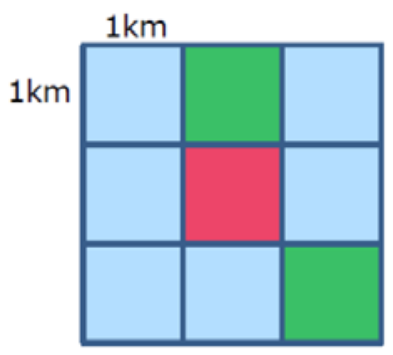

isolated

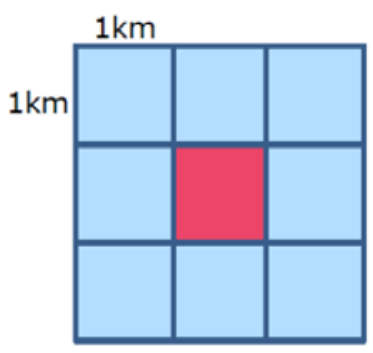

more isolated

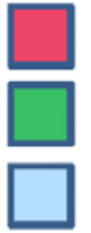

Grids which have only one non-Japanese and that person is female

Grids with non-Japanese

Grids with any population

Figure $1.1 \mathrm{~km} \mathrm{x} 1 \mathrm{~km}$ grids and degree of isolation 

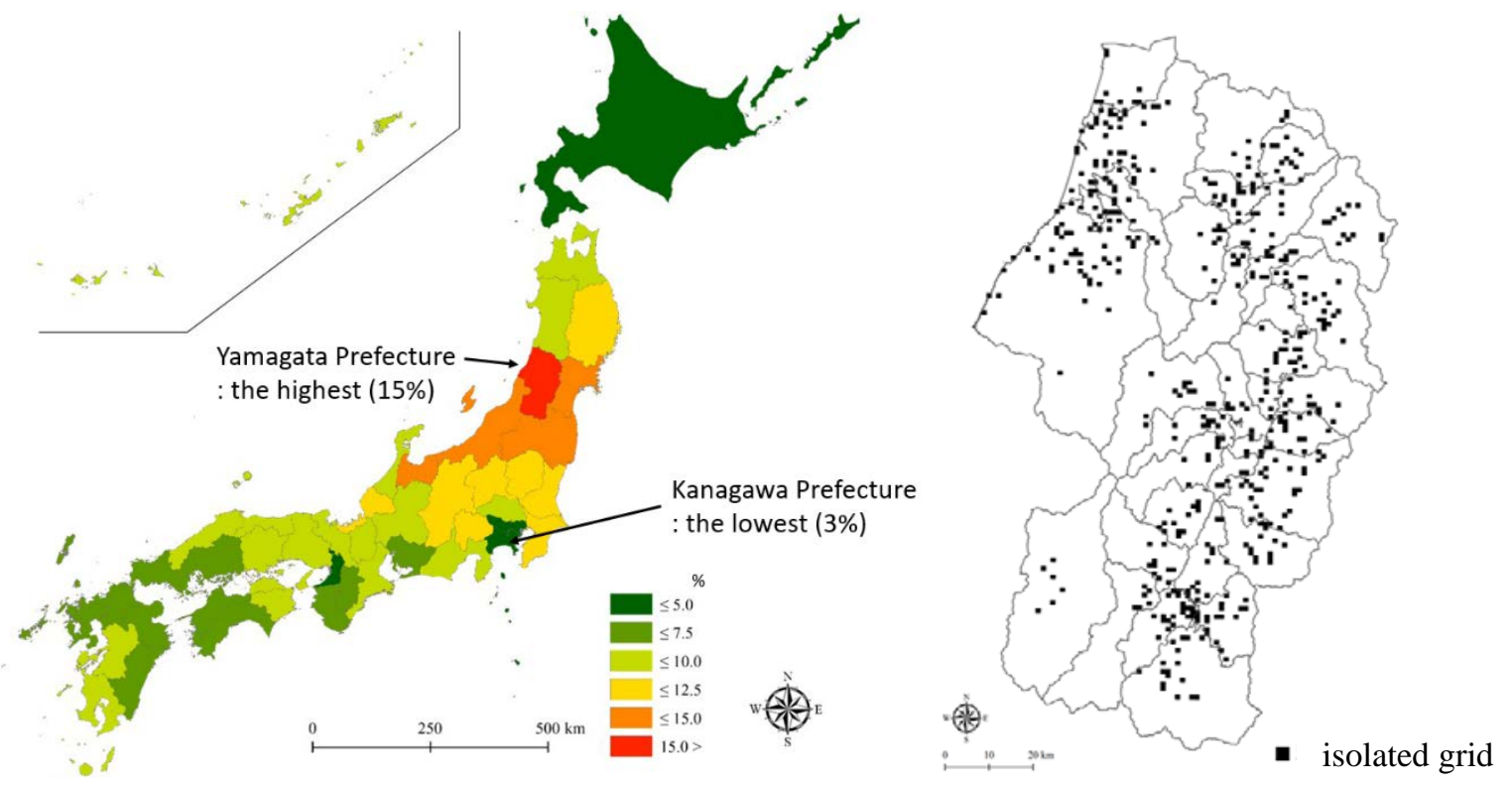

Figure 2. Proportions of grids which have only one non-Japanese and that person is female, i.e. isolated grids, in 47 prefectures of Japan (left) and distribution of isolated grids within Yamagata prefecture (right)
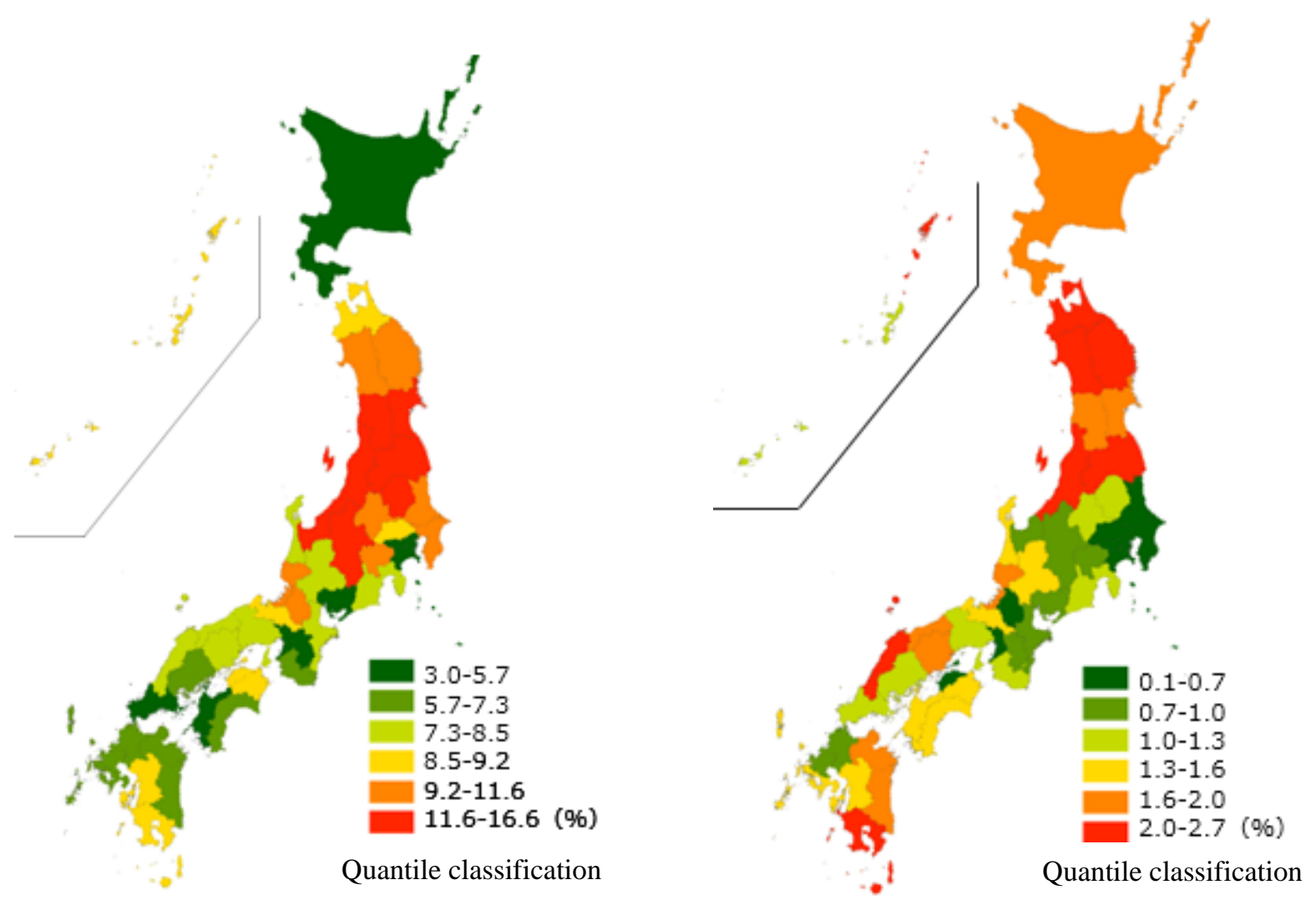

Figure 3. Comparison of distributions of isolated-grids (left) and more-isolated-grids (right) 